\title{
Opportunities to evaluate a landscape hydrological model (AWRA-L) using global data sets
}

\author{
Peña Arancibia J.L. ${ }^{1,3}$, Van Dijk A.I.J.M. ${ }^{1}$, Stenson, M.P. ${ }^{2}$ and N.R. Viney ${ }^{1}$ \\ ${ }^{1}$ CSIRO Land and Water GPO Box 1666, Canberra ACT 2601 Australia \\ ${ }^{2}$ CSIRO Land and Water, GPO Box 2583, Brisbane 4001, Australia \\ ${ }^{3}$ Environmental Monitoring and Modelling Research Group, Department of Geography, King's College \\ London, Strand, London WC2R 2LS, UK
}

Email: Jorge.PenaArancibia@csiro.au

\begin{abstract}
The Australian Water Resources Assessment system Landscape model (AWRA-L) aims to produce interpretable water balance component estimates covering all of Australia, and as much as possible agree with water balance observations, including point gauging data and satellite observations. The opportunities to evaluate AWRA-L water balance predictions in Australia are severely limited by the limited amount of field data (e.g. flux tower observations, soil moisture measurements) and the limited range of environments and conditions for which observations are available. Opportunities exist to further evaluate and improve AWRA-L model predictions by using global collations of in situ soil moisture, flux tower, and streamflow data available from the broader scientific community. To evaluate AWRA-L against these observations, global input data are required. We reviewed and compared results of published studies about meteorological data that could be used to parameterise AWRA-L globally. Review findings include:
\end{abstract}

- Satellite-based rainfall performs better during warm seasons and in the tropics, although overestimating total rainfall. Reanalysis data outperforms satellite-based rainfall during winter and in higher latitudes. Gauge bias-corrected TRMM 3B42V6 reduces observed bias in many areas globally. A blending approach may enhance rainfall quality estimates on a global scale, using rainfall from reanalysis in higher latitudes and satellite estimates such as TRMM 3B42V6 in mid-latitudes.

- Global monthly, annual and climatological surface temperature anomalies from reanalysis had very similar values. At the daily scale, compared daily maximum and minimum temperature probability density functions from ERA-40, JRA-25 and NCEP-DOE were dissimilar with large regional differences, but overall no reanalysis showed more skill than the other two when compared against regional observational temperature data.

- Surface shortwave radiation derived from satellite data generally has smaller biases than reanalysis because they are more constrained by observations. Of the three satellite-based incoming shortwave radiation estimates, GEWEX-SRB appeared superior to the other two. Globally, the biases in the climatology of the re-analyses are considerable.

The 60 year (1948-2008) Princeton Global Forcing (PGF) dataset with a spatial resolution of $1^{\circ}$ and daily time step was considered an adequate compromise for trial simulations. PGF is based on the NCEP/NCAR reanalysis but uses several additional data sources to constrain and reduce bias in the meteorological variables. We implemented a prototype $1^{\circ}$ resolution global hydrological model based on AWRA-L referred to here as the World-Wide Water Resources Assessment system (W3RA). W3RA was parameterized with the same set of parameters used in AWRA-L except for baseflow coefficient, which was derived from a global analysis of baseflow recession. In addition, a snow module was added to simulate snowmelt and snow accumulation. Other data used included land cover maps based on MODIS reflectance data, albedo climatology derived from white-sky albedo and wind speed climatology.

As part of preliminary evaluation of W3RA, runoff estimates were compared against a Global Runoff Data Centre (GRDC) blend of observations and modeled runoff climatology. Ongoing evaluation will include comparisons against a quality controlled gauged daily flows in 167 unimpaired catchments located mostly in the tropics, a global data set of collated site soil moisture measurements, and evapotranspiration from a global network of flux towers.

Keywords hydrology, global modelling, global data sets, AWRA-L, W3RA 


\section{INTRODUCTION}

The Australian Water Resources Assessment system Landscape model (AWRA-L) is a grid based distributed biophysical model that simulates water stores and flows in the vegetation, soil and local catchment groundwater systems (Van Dijk and Renzullo, 2011). As part of the requirements for model adoption in water balance assessment and water accounting for the whole of Australia, model outputs considered to provide a reliable indication of the quality of water balance were evaluated against observations (Van Dijk and Warren, 2010). Data used to perform model evaluation included daily streamflow data from over 300 catchments, eddy covariance flux tower evapotranspiration data at four sites, radar remote sensing (ASAR GM) derived top soil water content estimates and optical remote sensing (AVHRR, MODIS) derived vegetation fractional cover, leaf area index and greenness.

The opportunities to further evaluate AWRA-L water balance predictions in Australia are severely limited by the limited amount of field data. Flux tower observations and in situ soil moisture measurements only represent a limited range of environments and conditions for which observations are available. Global collations of in situ soil moisture, flux tower, and streamflow data available from the broader scientific community can be used to further evaluate and improve AWRA-L. Additional benefits of having the model implemented on a global scale would be to compare model estimates to results from other global models and further identify potential improvements in model structure or parameterisation. To evaluate AWRA-L against these observations, global spatial model input data sets are required, particularly of daily rainfall, radiation, temperature, soils, and land cover. A review of the data needed to parameterize a global version of AWRA-L; daily meteorological forcing in particular, is the main focus of this paper. Based on findings of from published studies, we implemented a $1^{\circ}$ resolution prototype "World-Wide Water Resources Assessment system" (W3RA). Simulated streamflow was compared with a Global Runoff Data Centre (GRDC) composite of observations and modeled runoff climatology (Fekete et al., 2002).

\section{METEREOLOGICAL FORCING DATA}

\subsection{Rainfall}

Seven satellite-based rainfall products and five global atmospheric reanalysis of meteorological observations were reviewed (Table 1; acronyms explained in cited references). Several studies have been conducted to evaluate different rainfall products from satellite, reanalysis and climatologic data sets by comparing them to ground observations in areas with reliable gauge or radar coverage or through their predictive capability of state variables such as soil moisture or streamflow from hydrological or land-surface models (e.g. Ebert et al., 2007; Tian et al., 2009; Pan et al., 2010; Tian and Peters-Lidard, 2010). Findings from most studies suggest a better agreement of satellite-based rainfall with baseline data over warm seasons whereas reanalysis rainfall outperformed the satellite estimates during the winter season on monthly and daily time-scales. It was also found in most studies that high (often convective) rainfall events are better captured by satellite estimates, although the amplitudes were generally overestimated (Ebert et al., 2007; Tian et al., 2009). The incorporation of surface rain gauge data, such as in TRMM 3B42V6, helped to reduce total errors; by adjusting the amplitudes of the hit biases and false precipitation. A global map of measurement uncertainties in daily satellite-based precipitation estimates were produced by Tian and Peters-Lidard (2010). Estimates tended to agree particularly well over areas with stronger precipitation, especially over the tropics. The performance at higher latitudes degraded considerably, especially above of $40^{\circ}$ latitude. This was due to coverage by fewer sensors (e.g., lack of TRMM coverage), light precipitation events, snowfall, and in the case of land surfaces, snow and ice on the ground which produce a signal similar to precipitation. Tian et al. (2009) found that daily satellite-based rainfall estimates in continental US constantly missed about 20-80\% of light precipitation $\left(<10 \mathrm{~mm} \mathrm{~d}^{-1}\right)$ and that the amount of false precipitation can occasionally be exceedingly large, especially for winter in western USA. During winter, missed precipitation was a major contributor to the total errors (up to 40\%) of TRMM-3B42RT, CMORPH, and PERSIANN, especially over complex terrain (Tian et al., 2009). 
Peña Arancibia et al., Opportunities for evaluation of AWRA-L using global datasets

Table 1. Main characteristics of daily or sub-daily global and quasi-global rainfall gridded data sets.

\begin{tabular}{|c|c|c|c|c|c|}
\hline Dataset & Grid resolution & Frequency & Coverage & Period & Reference \\
\hline \multicolumn{6}{|l|}{ Satellite } \\
\hline TRMM-3B42 (RT or V6) & $0.25^{\circ}$ & $3 \mathrm{~h}$ & $60^{\circ} \mathrm{S} \sim 60^{\circ} \mathrm{N}$ & $1998 \sim$ & Huffman et al. (2007) \\
\hline CMORPH & $0.08^{\circ} \sim 0.25^{\circ}$ & $0.5,3 \mathrm{~h}$ & $60^{\circ} \mathrm{S} \sim 60^{\circ} \mathrm{N}$ & $2002 \sim$ & Joyce et al. (2004) \\
\hline PERSIANN & $0.25^{\circ}$ & $3,6 \mathrm{~h}$ & $50^{\circ} \mathrm{S} \sim 50^{\circ} \mathrm{N}$ & $2000 \sim$ & Sorooshian et al. (2000) \\
\hline GPCP -1DD & $1^{\circ}$ & Daily & Global & $1996 \sim$ & Huffman et al. (2001) \\
\hline \multicolumn{6}{|l|}{ Reanalysis } \\
\hline ERA-40 & $1.125^{\circ}$ & $6 \mathrm{~h}$ & Global & $1957-2002$ & Uppala et al. (2005) \\
\hline ERA-Interim & $\sim 0.7^{\circ}$ & $6 \mathrm{~h}$ & Global & $1989 \sim$ & Simmons et al. (2007) \\
\hline NCEP-NCAR & $2.5^{\circ}$ & $6 \mathrm{~h}$ & Global & 1948 & Kalnay et al. (1996) \\
\hline NCEP-DOE & $2.5^{\circ}$ & $6 \mathrm{~h}$ & Global & $1957^{\sim}$ & Kanamitsu et al. (2002) \\
\hline JRA-25 & $1.25^{\circ}$ & $6 \mathrm{~h}$ & Global & 1979-2004 & Onogi et al. (2007) \\
\hline
\end{tabular}

Daily reanalysis rainfall from ERA-interim, followed by ERA-40 were considered more accurate than both NCEP reanalysis when compared to relatively dense global or local rainfall gauge networks (e.g. Pan et al., 2010) and generally outperformed the blended satellite estimates during the winter season over the continental USA, Australia, and Western Europe (Ebert et al., 2007). ERA-40 produced reasonable monthly rainfall comparisons over the Northern Hemisphere continents, with some notable biases, but less so in tropics where it had high positive bias, except for a negative bias over the Amazon during the rainy season (Betts et al., 2006; Bosilovich et al. 2008). The recent reanalysis JRA-25, showed good monthly rainfall comparisons in both the Northern Hemisphere continents and the tropical oceans, but varied in time according to the available observing systems, with additional satellite data improving precipitation and other hydrological data (Bosilovich et al. 2008). Rainfall in reanalysis data and impacts on water balance at a basin and global scale has been researched in some detail (Fekete et al., 2004). Results showed that rainfall biases lead to errors in water balance calculations and uncertainties of similar magnitude in humid areas and larger over arid and semi-arid areas. Several studies have aimed to address reanalysis rainfall errors by correcting for biases (e.g. Betts et al., 2005) with resulting improved water balances. Following this line, the $1^{\circ}$ and 3hourly 50-year daily meteorological Princeton Global Forcing (PGF) (1948-2008) dataset was developed by Sheffield et al. (2006). It was based on the NCEP-NCAR reanalysis and included corrections for known rainfall biases and rain day statistics using the latest global meteorological data sets and TRMM rainfall data. This dataset has been compared to ERA-40 and used in large-scale hydrological modelling to simulate soil moisture in the Yellow River Basin and showed better inter and intra-annual patterns ( $\mathrm{Li}$ and $\mathrm{Ma}, 2010$ ).

\subsection{Surface air temperature}

Absolute global daily temperature $\left(T_{a}\right)$ observations are available from reanalysis. Monthly, annual and climatological $T_{a}$ anomalies from aggregated daily estimates had very similar values in most reanalysis data sets including both ERA reanalysis, JRA-25 and NCEP-NCAR; when compared to station interpolated gridded global data sets such as HadCRUT3 (Simmons et al., 2004; Onogi et al., 2007). ERA-40 was closer to HadCRUT3 data than the NCEP-NCAR reanalysis, in all but the earliest years, reflecting the fact that surface observations were included in the ERA reanalysis (Simmons et al., 2004). At the daily temporal scale, Pitman and Perkins (2009) compared daily maximum and minimum $T_{a}$ probability density functions from ERA-40, JRA-25 and NCEP-DOE to regional observational data encompassing different environments in the absence of global observational data sets. Estimates of maximum $T_{a}$ had large regional differences but overall no reanalysis showed more skill than the other two. All reanalysis failed to match observations of maximum $T_{a}$ in the Amazon. For minimum $T_{a}$, all reanalysis showed reasonable agreement north of $\sim 45^{\circ} \mathrm{N}$, whereas ERA-40 appeared anomalous compared to the other reanalysis and to observations. Based on these results, Pitman and Perkins (2009) suggested the use of the 2-m air temperatures is not reliable and all reanalysis should be used independently to reflect uncertainty from input data. PGF also includes $T_{a}$ estimates, NCEP-NCAR $T_{a}$ was adjusted to match an earlier version of HadCRUT3 monthly and daily averages in order to correct for known temperature biases (Sheffield et al., 2006). 


\subsection{Surface radiation}

Global gridded radiation data sets, including incoming shortwave $\left(S W_{\text {down }}\right)$ and longwave $\left(L W_{\text {down }}\right)$ radiation, are available from satellite sensors and reanalysis. Existing literature shows that $S W_{\text {down }}$ and $L W_{\text {down }}$ derived from satellite data have generally smaller biases than reanalysis because they are more constrained by observations of atmospheric transmissivity (e.g. cloud cover) ( Betts et al., 2006). The International Satellite Cloud Climatology Project produced a global radiative flux data set (ISCCP-FD) on a 3-hourly, $280 \mathrm{~km}$ resolution for the period 1983-2006. Comparison of ISCCP-FD $S W_{\text {down }}$ with the Baseline Surface Radiation Network (BSRN) data (Ohmura et al., 1998) revealed a mean difference of $2 \mathrm{Wm}^{-2}$ and an RMSE error of 19 $\mathrm{Wm}^{-2}$ (Zhang et al., 2004). More recently, the GEWEX Surface Radiation Budget (GEWEX-SRB) Project has constructed a 24.5-year (July 1983 to December 2007) data set of surface $S W_{\text {down }}$ and $L W_{\text {down }}$ radiative fluxes (Stackhouse et al., 2011). GEWEX SRB release 3.0 is produced on a $1^{\circ}$ and 3 -hourly resolution using satellite-derived cloud parameters and ozone fields, reanalysis meteorology, and a few other ancillary data sets. Validation of monthly average downward $S W_{\text {down }}$ and $L W_{\text {down }}$ fluxes with BSRN sites mean bias for $\mathrm{SW}_{\text {down }}$ fluxes is $\sim-4 \mathrm{~W} \mathrm{~m}^{-2}$ with an RMSE difference of $23 \mathrm{~W} \mathrm{~m}^{-2}$. An examination of individual sites showed that most of this underestimation arose at polar sites; especially those located on the Antarctic coast, but these are much improved over previous versions (Stackhouse et al., 2011). Corresponding bias for the $L W_{\text {down }}$ fluxes are only about $-0.1 \mathrm{~W} \mathrm{~m}^{-2}$ with an RMSE difference of $11 \mathrm{~W} \mathrm{~m}^{-2}$.

The Earth's Radiant Energy System Radiative Fluxes and Clouds instrument (CERES-FSW) provides $S W_{\text {down }}$ and $L W_{\text {down }}$ fluxes on a $1^{\circ}$ and daily resolution. Gupta et al. (2004) evaluated instantaneous-footprint $S W_{\text {down }}$ and $L W_{\text {down }}$ fluxes from January-August 1998 against high quality ground-based radiometric measurements from several sites of the BSRN data set. For this instantaneous-footprint $S W_{\text {down }}$ fluxes had significant biases in some sites, and random errors were much larger than acceptable values.

Gui et al. (2010) compared 3-hourly or hourly (when available) $S W_{\text {down }}$ measurements for the period 20002002 from ISCCP-FD, GEWEX-SRB and CERES-FSW $S W_{\text {down }}$ against 36 stations from five different ground measurement networks. Results showed that SRB met accuracy criteria in most regions, followed by FD and FSW. Both SRB and FD underestimated $S W_{\text {down }}$ in the Tibetan Plateau and Greenland and had large biases and overestimation in Southeast Asia. In addition, FD had slight overestimation in the Amazon. FSW had low correlations, had large biases and overestimates ground measurements in the Tibetan Plateau and Southeast Asia, as well as large overestimation in North America and the Amazon. The Princeton Global Forcing data set (PGF) $S W_{\text {down }}$ adjusts the systematic biases in NCEP-NCAR data using the GEWEX-SRB climatology and a historic cloud data set.

\section{IMPLEMENTATION OF W3RA AND DATA EVALUATION AGAINST GRDC COMPOSITE RUNOFF DATA}

A global version of the Australian Water Resources Assessment system Landscape model (AWRA-L) (version 0.5; Van Dijk and Renzullo, 2011) was implemented on a $1^{\circ}$ grid cell resolution, referred to here as the "World-Wide Water Resources System" (W3RA). Bias-corrected Princeton Global Forcing (PGF) precipitation, incoming short wave radiation; minimum and maximum daily temperature and air pressure data were used as meteorological inputs. The parameters used in W3RA were derived from observations in Australia through analysis performed as part of development of AWRA-L or derived from literature. Baseflow coefficient was estimated using relationships found in a global analysis of baseflow recession (Peña-Arancibia et al., 2010). This version of the model included two hydrological response units (HRUs): deep-rooted tall vegetation (forest) and shallow-rooted short vegetation (herbaceous). In each HRU, the model simulates the water balance on three soil stores (top, shallow and deep soil compartment) whereas groundwater and surface water are simulated at catchment scale. In addition, the HBV-96 snow hydrology module was included to simulate snowmelt and snow accumulation (Bergström and Singh, 1995). To represent each $\mathrm{HRU}$, the $0.05^{\circ}$ resolution vegetation continuous fields derived from MODIS reflectance data (2000-2001) (Hansen et al., 2003) was aggregated to a $1^{\circ}$ grid cell resolution land/sea mask. Other data sets used to parameterise the model included an albedo climatology derived from white-sky albedo (Moody et al., 2005) and wind speed climatology (1983-1993) from NASA. The model warm-up used the full 61 years of the PGF data (1948-2008), the model was then rerun using the states reached at the end of 2008. This was done due to the long time (around three decades) needed for deeper soil stores in arid regions to reach dynamic equilibrium.

As a preliminary evaluation of the W3RA estimates, the climatology (1950-1979) of quasi-global blended modeled runoff and river streamflow observation station network (Fekete et al., 2002) was used as baseline to evaluate W3RA runoff results over the same time-period. To produce spatially distributed runoff, simulated runoff above a gauging station was scaled using correction coefficients to match river streamflow. 


\section{PRELIMINARY RESULTS}

Figure 1a and $\mathrm{b}$ show the spatial distribution of W3RA and the GRDC composite mean annual log-scaled runoff for the period 1950-1979 respectively. Spatial patterns are captured particularly well in the humid tropical areas and North America, whereas W3RA produces lower runoff estimates in Europe and parts of northern Asia and higher runoff in very arid areas. Computed mean values across the latitude band $70^{\circ} \mathrm{N}-$ $50^{\circ} \mathrm{S}$ show that W3RA performs better in latitudes above $0^{\circ} \mathrm{N}$ and overestimates runoff in lower latitudes (Fig. 1c). This overestimation may be related to a higher number of streamflow stations with better accuracy in northern latitudes (see Hong et al., 2008). The landmass above $70^{\circ} \mathrm{N}$ was not used in comparisons since there were no GRDC composite runoff data. Mean annual runoff was $310( \pm 225) \mathrm{mm} \mathrm{y}^{-1}$ for W3RA and 345 $( \pm 270) \mathrm{mm} \mathrm{y}^{-1}$ for GRDC composite runoff. Correlation coefficient $\left(\mathrm{R}^{2}\right)$ and relative bias were 0.87 and $10 \%$ respectively. W3RA produces streamflow estimates that are higher than GRDC estimates for arid areas in the southern hemisphere. It is noted that the W3RA estimates should be interpreted as local catchment runoff, whereas the GRDC data are scaled to conform to river flows observed at the end of large catchments and therefore implicitly include river losses. This may explain the discrepancy for arid zones, where closed catchments are common and internal catchment losses considerable, e.g. in the Australian interior.

(a) W3RA

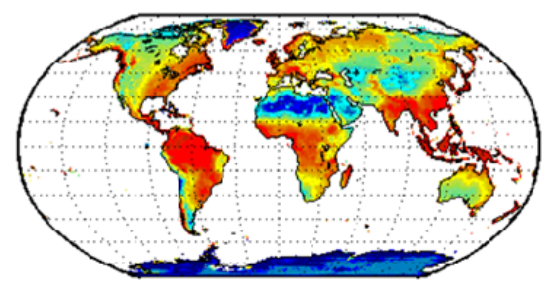

(b) GRDC comp

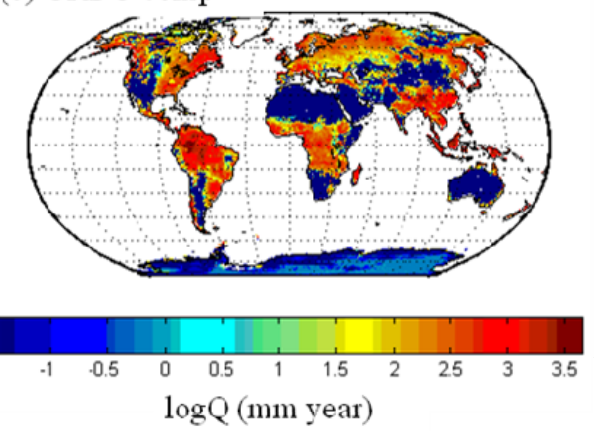

(c)

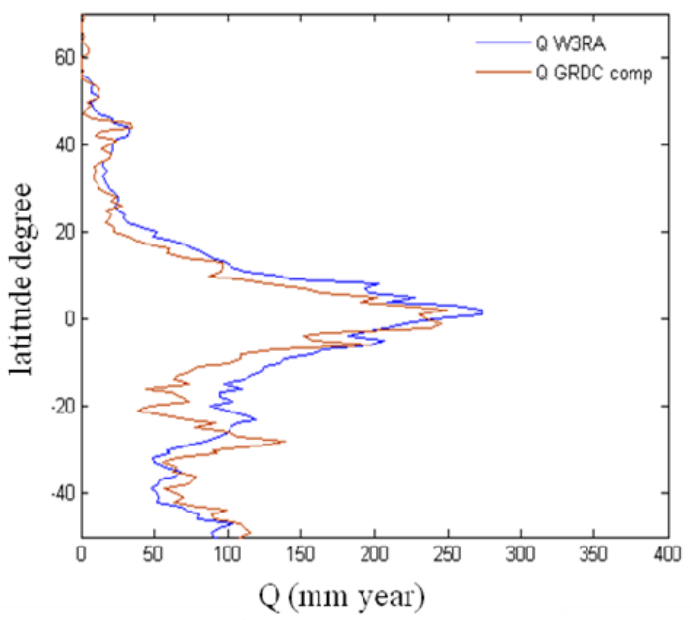

Figure 1. (a) Mean annual log-scaled runoff from W3RA for the period 1950-1979. (b) Mean annual log-scaled runoff from GRDC composite fields (1950-1979). (c) Mean latitudinal profiles comparing W3RA (blue) and GRDC (red). Means are computed by assigning a value of 0 to ocean cells in order to avoid deviations for latitude bands with few terrestrial cells.

\section{SUMMARY AND FURTHER MODEL EVALUATION}

We reviewed published studies of satellite-derived, reanalysis and gauge-based data with global or nearglobal coverage and which are routinely used in hydrological modelling. Satellite-based rainfall performed better during warm seasons and in the tropics, capturing large events better than reanalysis, although overestimating total rainfall. Daily satellite-based rainfall estimates generally missed light precipitation and the amount of false precipitation also gets exceedingly large sometimes, especially for winter. Gauge biascorrected TRMM 3B42V6 reduced observed bias in many areas globally, however large discrepancies still exists in areas with complex topography. Reanalysis data outperformed satellite-based rainfall during winter and in higher latitudes. In this respect, a blending approach may enhance rainfall quality estimates on a global scale, using rainfall from reanalysis in higher latitudes and satellite estimates such as TRMM 3B42V6 in mid-latitudes.

Monthly, annual and climatological $T_{a}$ anomalies from aggregated daily estimates had very similar values in most reanalysis data sets including both ERA reanalysis, JRA-25 and NCEP-NCAR; when compared to the observational network HadCRUT3, with both ERA and JRA-25 having a closer agreement to HadCRUT3 
than NCEP-NCAR. At the daily scale, compared daily maximum and minimum $T_{a}$ probability density functions from ERA-40, JRA-25 and NCEP-DOE were dissimilar with large regional differences, but overall no reanalysis showed more skill than the other two when compared against regional observational temperature data.

Surface shortwave radiation $S W_{\text {down }}$ derived from satellite data have generally smaller biases than reanalysis because they are more constrained by observations. Of the three satellite-based incoming shortwave radiation estimates, GEWEX-SRB appeared superior to the other two. Globally, the biases in the climatology of the re-analyses are significant, more for NCEP-DOE than ERA-40.

The 60 year (1948-2008) Princeton Global Forcing (PGF) dataset with a spatial resolution of $1^{\circ}$ and daily time step was considered an adequate compromise for trial simulations. PGF, based on the NCEP/NCAR reanalysis, used many of the data described above to constrain and reduce bias of its meteorological variables. W3RA was parameterized with the same set of parameters used in AWRA-L expect for baseflow coefficient, which was derived from a global analysis of baseflow recession. The prototype W3RA global hydrological model produced encouraging runoff estimates without substantially modifying the model structure or the parameters that were used to simulate the water balance for Australian conditions. Runoff corresponded closely to a blended data comprised of observations and modeled runoff.

Further model evaluation against streamflow will be performed using carefully quality-controlled global data sets of streamflow from small and unimpaired catchments (e.g. Peña-Arancibia et al., 2010). W3RA soil moisture estimates will be evaluated against a collated international data set of in situ measurements (Dorigo et al., 2011), and evapotranspiration estimates will be evaluated against a set of high quality FLUXNET site measurements covering a variety of ecosystems (cf. Miralles et al., 2011).

\section{REFERENCES}

Bergström, S., Singh, V.P., (1995), The HBV model. Water Resources Publications: 443-476.

Betts, A. K., M. Zhao, P. A. Dirmeyer, and A. C. M. Beljaars (2006), Comparison of ERA40 and NCEP/DOE near-surface data sets with other ISLSCP-II data sets, Journal of Geophysical ResearchAtmospheres, 111(D22).

Betts, A. K., J. H. Ball, P. Viterbo, A. Dai, and J. Marengo (2005), Hydrometeorology of the Amazon in ERA-40, Journal of Hydrometeorology, 6(5), 764-774.

Bosilovich, M. G., J. Y. Chen, F. R. Robertson, and R. F. Adler (2008), Evaluation of global precipitation in reanalyses, Journal of Applied Meteorology and Climatology, 47(9), 2279-2299.

Dorigo, W.A., W.Wagner, R. Hohensinn, S. Hahn, C. Paulink, M. Drusch, S. Mecklenburg, P. van Oevelen, A. Robock and T. Jackson (2011), The International Soil Moisture Network: a data hosting facility for global in situ soil moisture measurements. Hydrology and Earth System Sciences, 15, 1675-2011.

Ebert, E. E., J. E. Janowiak, and C. Kidd (2007), Comparison of near-real-time precipitation estimates from satellite observations and numerical models, Bulletin of the American Meteorological Society, 88(1), 47.

Fekete, B. M. , Vörösmarty, C. J. \& Grabs, W. (2002), High-resolution fields of global runoff combining observed river discharge and simulated water balances. Glob. Biogeochem. Cycles 16, 1042.

Fekete, B. M., C. J. Vorosmarty, J. O. Roads, and C. J. Willmott (2004), Uncertainties in precipitation and their impacts on runoff estimates, Journal of Climate, 17(2), 294-304.

Gui, S., S. L. Liang, K. C. Wang, L. Li, and X. T. Zhang (2010), Assessment of Three Satellite-Estimated Land Surface Downwelling Shortwave Irradiance Data Sets, IEEE Geoscience and Remote Sensing Letters, 7(4), 776-780.

Gupta, S. K., D. P. Kratz, A. C. Wilber, and L. C. Nguyen (2004), Validation of parameterized algorithms used to derive TRMM-CERES surface radiative fluxes, Journal of Atmospheric and Oceanic Technology, 21(5), 742-752.

Hansen, M. C., R. S. DeFries, J. R. G. Townshend, M. Carroll, C. Dimiceli, and R. A. Sohlberg (2003), Global Percent Tree Cover at a Spatial Resolution of 500 Meters: First Results of the MODIS Vegetation Continuous Fields Algorithm, Earth Interactions, 7.

Hong, Y., R. F. Adler, F. Hossain, S. Curtis, and G. J. Huffman (2007), A first approach to global runoff simulation using satellite rainfall estimation, Water Resour. Res., 43, W08502.

Huffman, G. J., R. F. Adler, M. M. Morrissey, D. T. Bolvin, S. Curtis, R. Joyce, B. McGavock, and J. Susskind (2001), Global precipitation at one-degree daily resolution from multisatellite observations, Journal of Hydrometeorology, 2(1), 36-50.

Huffman, G. J., R. F. Adler, D. T. Bolvin, G. J. Gu, E. J. Nelkin, K. P. Bowman, Y. Hong, E. F. Stocker, and D. B. Wolff (2007), The TRMM multisatellite precipitation analysis (TMPA): Quasi-global, multiyear, combined-sensor precipitation estimates at fine scales, Journal of Hydrometeorology, 8(1), 38-55. 
Joyce, R. J., J. E. Janowiak, P. A. Arkin, and P. P. Xie (2004), CMORPH: A method that produces global precipitation estimates from passive microwave and infrared data at high spatial and temporal resolution, Journal of Hydrometeorology, 5(3), 487-503.

Kanamitsu, M., W. Ebisuzaki, J. Woollen, S.K. Yang; J.J. Hnilo; M. Fiorino; G.L. Potter (2002), NCEPDOE AMIP-II reanalysis (R-2). Bulletin of the American Meteorological Society, 83(11): 1631-1643.

Kalnay, E., et al. (1996), The NCEP/NCAR 40-year reanalysis project, Bulletin of the American Meteorological Society, 77(3), 437-471.

Li, M. X., and Z. G. Ma (2010), Comparisons of Simulations of Soil Moisture Variations in the Yellow River Basin Driven by Various Atmospheric Forcing Data Sets, Advances in Atmospheric Sciences, 27(6), 1289-1302.

Miralles, D. G., T. R. H. Holmes, R. A. M. d. Jeu, J. H. Gash, A. G. C. A. Meesters, and A. J. Dolman (2011), Global land-surface evaporation estimated from satellite-based observations, Hydrology and Earth System Sciences, 15(2), 453-469.

Moody, E.G., King, M.D., Platnick, S., Schaaf, C.B., Feng, G., (2005), Spatially complete global spectral surface albedos: value-added datasets derived from Terra MODIS land products. Geoscience and Remote Sensing, IEEE Transactions on, 43(1): 144-158.

Ohmura, A., et al. (1998), Baseline Surface Radiation Network (BSRN/WCRP): New precision radiometry for climate research, Bulletin of the American Meteorological Society, 79(10), 2115-2136.

Onogi, K., et al. (2007), The JRA-25 reanalysis, Journal of the Meteorological Society of Japan, 85(3), 369432.

Pan, M., H. B. Li, and E. Wood (2010), Assessing the skill of satellite-based precipitation estimates in hydrologic applications, Water Resources Research, 46.

Peña-Arancibia, J. L., A. van Dijk, M. Mulligan, and L. A. Bruijnzeel (2010), The role of climatic and terrain attributes in estimating baseflow recession in tropical catchments, Hydrology and Earth System Sciences, 14(11), 2193-2205.

Pitman, A. J., and S. E. Perkins (2009), Global and regional comparison of daily 2-m and 1000-hPa maximum and minimum temperatures in three global reanalyses, Journal of Climate, 22(17), 46674681.

Sheffield, J., G. Goteti, and E. F. Wood (2006), Development of a 50-year high-resolution global dataset of meteorological forcings for land surface modeling, Journal of Climate, 19(13), 3088-3111.

Simmons, A. J., P. D. Jones, V. D. Bechtold, A. C. M. Beljaars, P. W. Kallberg, S. Saarinen, S. M. Uppala, P. Viterbo, and N. Wedi (2004), Comparison of trends and low-frequency variability in CRU, ERA-40, and NCEP/NCAR analyses of surface air temperature, Journal of Geophysical Research-Atmospheres, 109(D24).

Simmons, A., S. Uppala, D. Dee, and S. Kobayashi, (2007), ERA-Interim: New ECMWF reanalysis products from 1989 onwards. ECMWF Newsletter No 110, 25-35.

Sorooshian, S., K. L. Hsu, X. Gao, H. V. Gupta, B. Imam, and D. Braithwaite (2000), Evaluation of PERSIANN system satellite-based estimates of tropical rainfall, Bulletin of the American Meteorological Society, 81(9), 2035-2046.

Stackhouse P.W., Gupta S.K., Cox S.J., Zhang T., Mikovitz J.C., Hinkelman L.M. (2011) 24.5-Year SRB Data Set Released. GEWEX News, 21(1)

Suttles J.T., and Ohring G., (1986) Surface radiation budget for climate applications. NASA 1169, $136 \mathrm{pp.}$

Tian, Y., and C. Peters-Lidard (2010), A global map of uncertainties in satellite-based precipitation measurementsGeophysical Research Letters, 37(L24407), 1-6

Tian, Y. D., C. D. Peters-Lidard, J. B. Eylander, R. J. Joyce, G. J. Huffman, R. F. Adler, K. L. Hsu, F. J. Turk, M. Garcia, and J. Zeng (2009), Component analysis of errors in satellite-based precipitation estimates, Journal of Geophysical Research-Atmospheres, 114.

Uppala, S. M., et al. (2005), The ERA-40 re-analysis, Quarterly Journal of the Royal Meteorological Society, 131(612), 2961-3012.

Van Dijk, A.I.J.M, Renzullo, L.J., (2011), Water resource monitoring systems and the role of satellite observations. Hydrology and Earth System Sciences, 15: 39-55.

Van Dijk, A. I. J. M., and Warren, G. (2010), The Australian Water Resources Assessment System. Technical Report 4. Landscape Model (version 0.5) Evaluation Against Observations. CSIRO: Water for a Healthy Country National Research Flagship.

Zhang, Y. C., W. B. Rossow, A. A. Lacis, V. Oinas, and M. I. Mishchenko (2004), Calculation of radiative fluxes from the surface to top of atmosphere based on ISCCP and other global data sets: Refinements of the radiative transfer model and the input data, Journal of Geophysical Research-Atmospheres, 109(D19). 